\title{
Increasing systemic capacity to respond to child and adolescent mental health needs using reciprocal knowledge transfer with parents
}

Susan Croom Newcastle and North Tyneside NHS Mental Health Trust, Northumberland, UK and Susan Procter Adult Nursing Department, City Community and Health Sciences, City University, London, UK

\begin{abstract}
Background: Knowledge is recognized as a crucial organizational resource, which it has been suggested, increases in value through use. However, tensions exist between applying generalized scientific and academic knowledge to practice and incorporating local, experiential and tacit understanding in our knowledge base for practice. Knowledge management and transfer are frequently advocated as the means to increase service capacity within existing resource levels. In the NHS knowledge management and transfer tends to adopt a social constructivist approach, which favours the application of scientific evidence to practice, consequently the tacit and experiential knowledge of practitioners and service users is often excluded from formal knowledge-transfer processes. Aim: This paper describes a systematic process that was used to formalize tacit nursing knowledge in child and adolescent mental health $(\mathrm{CAMH})$ and link it into the pre-existing scientific and academic literature. Method: The paper goes on to describe how this process was modified and transferred to work with parents of children referred to CAMH services. Findings: The paper illustrates the differing strands of pre-existing scientific and academic knowledge valued by nurses and parents. It highlights how involving service users in identifying scientific and academic knowledge that they find useful can focus attention on strands of pre-existing knowledge previously overlooked by professionals and service providers and thus enhance the value of this knowledge as an organizational resource. The paper also demonstrates how the tacit and experiential knowledge of nurses and services users can be transformed into more formalized knowledge, which can then be incorporated into organizational knowledge-transfer processes.
\end{abstract}

Key words: child and adolescent mental health; knowledge management and transfer; parents and service users; practice knowledge; systemic capacity

Received: October 2006; accepted: November 2007

\section{Introduction}

Knowledge is increasingly recognized as a critical organizational resource (Stewart, 2002; Davenport

Address for correspondence: Professor Susan Procter, Adult Nursing Department, City Community and Health Sciences, City University, Philpot Street, London E1 2EA, UK. Email: s.procter@city.ac.uk and Prusak, 1998), which is unique as it increases in value through use (Probst et al., 2000). In the UK, as in other health care systems, a range of policy initiatives have been introduced that set practice and service delivery guidelines based on the best available evidence. These include in the UK the introduction of National Service Frameworks (NSFs) for a range of conditions and the establishment of the National Institute for Health

C) 2008 Cambridge University Press 
and Clinical Effectiveness (NICE). In the US, the Agency for Health Care Research and Quality and in Australia the National Institute for Clinical Studies have been established to promote evidence-based practice.

Evidence-based guidelines are usually derived from knowledge obtained using scientific methods and codify explicit expert knowledge (Cochrane, 1972; Sackett and Rosenberg, 1995). Knowledge, however, encompasses more than formal codified and scientifically derived evidence, it also encompasses tacit understanding (Baumard, 1999) that is "engrained in the analytical and conceptual understandings of individuals (the "know what" knowledge) and also embodied in their practical skills and expertise (their "know how")' (Bate and Robert, 2002). The WHO (2006, p. 1) discusses how: 'Bridging the know-do gap is one of the most important challenges for public health in this century. It poses the greatest opportunity for strengthening health systems and ultimately achieving equity in global health. Knowledge translation is emerging as a paradigm towards closing that gap' [our italics]. The WHO (2006) acknowledges that despite a range of innovative examples of knowledge transfer, there is no comprehensive platform for understanding how knowledge (ie, what we know) can be effectively utilized (ie, what we do) to promote optimum health within a given set of resources and circumstances. The WHO argues that developing this platform will require that relevant parties engage in awareness building, joint learning and improved methodologies for knowledge synthesis and exchange. This paper describes a methodology designed to support reciprocal knowledge transfer between health policy, scientific and academic knowledge and nursing and parental practice knowledge in child and adolescent mental health (CAMH).

\section{Background}

Sociological discussions of the knowledge base for professional practice focus on an abstract and theoretical critique of professional knowledge and power (Johnson, 1995; Turner, 1995) and its impact on service users. The use of codified knowledge derived from rational, scientific and systematic analysis is seen as fundamental in

Primary Health Care Research \& Development 2008; 9: 49-63 distinguishing professional knowledge from lay or everyday knowledge, professionals are distinguished by their access to and authority to use this knowledge in practice. Early practice debates, however, highlighted the limitations of traditional academic approaches in providing knowledge to inform practice, arguing academic knowledge was too abstract and generalized to be of much practical value in helping practitioners address specific everyday practice problems and situations (Agyris, 1993; Schon, 1983, 1987). This position is disputed in health care by proponents of evidencebased medicine who highlight the benefits of applying rigorously tested interventions and knowledge derived using scientific methods to practice (Sackett and Rosenberg, 1995; Muir Gray, 1997; Centre for Reviews and Dissemination, 2001).

The tensions that exist between generalized scientific and academic knowledge as a basis for professional practice, and the impact of local experiential and tacit knowledge on that practice, give rise to debates about how effectiveness is conceived, achieved and maintained in everyday practice contexts (Reed and Biott, 1995; RyecroftMalone et al., 2004; Rolfe, 2000; Maturana, 1991). This has led Bate and Robert (2002) to comment (in a review of the application to the NHS, of lessons learnt about knowledge management in the private sector) that "while the NHS has been vigorously promoting evidence-based medicine and the use of explicit, expert knowledge in clinical practice, the private sector has been moving in the opposite direction, stressing the value of intuitive, tacit knowledge' found in the heads of employees.

As a result of this debate, increasing recognition is being given to the oversimplified understanding of knowledge for practice that occurs when practice is split up, for academic purposes, into discrete strands, themes, systems, or methodological perspectives that are tested and theorized in isolation from each other (Miller and Crabtree, 2000; Kemmis and McTaggart, 2000). More recently, the full complexity of identifying the knowledge base for practice has been mapped out by Pawson et al. (2004) who state:

The problem is one of complexity. The health interventions in question are not singular schemes or finite treatments but 
concern the design, implementation, management and regulation of entire services. These services have a multiplicity of goals, many of them relating to the fulfilment of long-term ambitions. By the same token, the evidence base for health service decision making is also gargantuan. In getting to grips with so many activities of so many actors, the seeker of evidence has to call on the entire repertoire of social science and health services research. A review may thus involve a dissection of experimental and quasiexperimental trials, process and developmental evaluations, ethnographic and action research, documentary and content analysis, surveys and opinion polls. Even this formidable list overlooks the pearls of wisdom to be found in the grey literature, including administrative records, annual reports, legislative materials, conceptual critique, personal testimony and so on.

$$
\text { (Pawson et al., 2004, p. iii) }
$$

But even this powerful statement of the problem of deriving knowledge for practice overlooks a crucial aspect of the knowledge transfer debate and that is the skills, knowledge (both explicit and tacit) and analytical and conceptual understandings of the service users themselves. The importance of engaging with service users as active research participants is increasingly advocated (Khanlou and Peter, 2005; INVOLVE). However, the inclusion of service users in the literature on knowledge creation and transfer is in its infancy and forms a key focus for this paper.

One way of addressing the problem created by tacit knowledge in professional practice is to convert tacit knowledge to explicit knowledge through a process of dialogue and the codification of tacit understanding into explicit transferable knowledge (Bate and Robert, 2002). According to Bate and Robert (2002), this process of knowledge creation improves its 'fluidity' or 'transferability' across organizational boundaries. This paper considers how these processes, which have been developed to support knowledge transfer within and between organizations, can be adapted and used to involve service users in a process of knowledge creation that codifies their tacit expertise, enabling it to transfer into both practice and policy contexts.

\section{Translating CAMH research and policy into action}

Standard nine of the NSF for Children Young People and Maternity Services (DoH and DfES, 2004) recognizes the need to improve mental health services for children and adolescents through multi-agency working and an evidencebased approach to practice and service provision. Achieving this requires a fundamental shift in thinking about health and social service provision in order to develop services that are designed and delivered around the needs of children and families (DoH and DfES, 2004). The messages in the NSF are very similar to those enshrined in earlier CAMH policy documents (Health Advisory Service, 1995; Audit Commission, 1999; Mental Health Foundation, 1999). The lack of progress in implementing policy and evidence in practice, indicated by repeated national policy objectives over an extended period, suggest a major difficulty in policy implementation in this area. An analysis of these documents highlights a number of areas where problems are seen to persist over several decades despite repeated efforts on the part of policy makers, researchers and professionals to address them. These are given in Box 1.

While the problems listed in Box 1 are well known to CAMH practitioners, researchers and policy makers and have been discussed extensively in the literature (Cunningham et al., 1996; Webster-Stratton, 1998), the know-do gap applies, as little attempt is made to acknowledge, theorize or address these challenges in practice and service delivery (doing) strategies. Instead CAMH services tend to adhere to socially constructed models for knowledge transfer and management as described by Bate and Robert (2002) and McAdam and Reid (2001). Socially constructed models of knowledge management and transfer are considered to be appropriate for understanding knowledge transfer in organizational settings as they 'assume a wide definition of knowledge and represent knowledge as being intrinsically linked to the social and learning processes within the organisation' (McAdam and Reid, 2001).

However, a focus on knowledge creation and transfer derived from organizational and professional understandings of problems and solutions rather than population experience is unlikely to

Primary Health Care Research \& Development 2008; 9: 49-63 


\section{Box 1}

1. In the area of CAMH there are high needs with a prevalence of at least $10 \%$ (Office of National Statistics, 2005) and finite resources. The importance of optimizing current resources by maximizing universal (services available to all) targeted (services aimed at those known to be at risk of developing $\mathrm{CAMH}$ problems) and specialist services (for those suffering from diagnosed CAMH disorders) has been a consistent feature of CAMH policy in the UK (Health Advisory Service, 1995; Audit Commission, 1999; DoH and DfES, 2004). Policy in the UK has consistently recognized that $\mathrm{CAMH}$ needs cannot be met by clinical services alone, yet the majority of expenditure in CAMH is still linked to clinical models of care (Pawson et al., 2004; Knapp et al., 1999).

2. CAMH researchers have recognized the know-do gap in CAMHs. Evidence derived from experiments using randomized controlled trials is found not to be as effective when actually applied in practice (Henggeler et al., 1995; Pawson et al., 2004). This becomes particularly acute when attempting to make evidence-based approaches to practice accessible and acceptable to the most vulnerable clients (Cunningham et al., 1995). This highlights the need to develop a knowledge-based rather than just evidence-based approach to CAMH practice.

3. The sociological critiques of professional power and control over knowledge form a central issue in understanding the impact of knowledge transfer activities on the effectiveness of service delivery and the implementation of policy objectives. CAMH services are currently dominated by professionals who are ascribed power through legitimated knowledge, derived predominantly from scientific research using experimental methods that control for variation in individual user attitudes and beliefs (Prillitinsky, 2001). This sets up didactic programmes that create an unequal power relationship between professionals and parents, making reciprocal knowledge transfer, fundamental to family-centred practice, difficult to achieve.

Primary Health Care Research \& Development 2008; 9: 49-63 address the challenges to meeting the needs of the CAMH population highlighted in Box 1 . Excluding service users from knowledge creation and transfer processes means that the knowledge found useful and therefore valued by service users goes unrecognized in policy, practice and service development strategies. At the same time, the social constructivist models of knowledge creation and transfer found in the NHS perpetuate the knowledge and experience of professionals, along with the limitations of this knowledge base in addressing key problems, often leading to repetitive cycles of initiatives as demonstrated in the above policy documents.

This paper describes how findings from a nursing study (Croom et al., 2000) were tested, in a subsequent study, for their relevance with parents of children in receipt of CAMH services (Croom and Procter, 2005). The paper describes the methodological challenges and solutions adopted in developing reciprocal knowledge transfer between nurses and clients. Separate approval for each study was obtained from the local research ethics committee.

\section{Background to the Nursing Study}

The nursing study used action research with experienced nurses working in a regional, residential CAMH unit (Croom et al., 2000). The nurses identified that a critical practice problem for them in providing 24-h care was how to help children to develop a sense of 'control', which enabled them to cope with everyday frustrations without either becoming a danger to themselves or to others or interfering with their capacity to meet their social, emotional and developmental goals. This focus was supported by the literature (Caspi et al., 1995; Wenar, 1982; Cunningham et al., 1995). The nursing study began with a concept analysis of control, which was used to structure a wide body of literature that identified the essential elements of the concept (Cutcliffe and McKenna, 2005). The defining attributes of the concept analysis were attachment, information processing and the use of a pause to engage feedback and emotional regulation.

The literature associated with these attributes was then examined by the nurses using critical incidents of practice situations they encountered in the CAMH unit. Through this process 
additional attributes of ambivalence, reciprocal emotional arousal, peer relationships between children and the child's help-seeking behaviour were identified as critical components of practice knowledge required to help a child develop a sense of control appropriate to their developmental age. The literature associated with these attributes was examined by the nurses as a means of integrating theoretical and empirical-based evidence with practice knowledge (Croom et al., 2000). The subsequent study with parents used participant action research (Khanlou and Peter 2005) and critical social theory (Fontana, 2004) to explore with parents attending a parenting group, the relevance of the findings from the nursing study to the parents' everyday 24-h situation looking after children referred to the CAMH Unit.

\section{Developing theoretical link between the transfer and development of knowledge in the nursing study and the parental study}

A key finding that emerged from the nursing study was that the nurses found engaging in the reciprocal exchange of knowledge between published evidence and practice was valuable in both developing and clarifying their practice and to codifying their experiential knowledge, making it accessible to other members of the multidisciplinary team. Together the experiential and the published knowledge provided a framework of practice, which was useful in the nurses' practice context (Croom et al., 2000). However, this raised questions about the relevance and usefulness of this framework to the parents to whom these children were discharged. Could access to this knowledge help them in looking after their child with challenging behaviours at home?

This concern gave rise to the following analytical research questions, which formed the aims for the subsequent study with parents:

- To identify whether the nursing knowledge and skills were useful and relevant to parents of children with behaviour problems, in the context of their 24-h everyday care of these children in their community.

- What other knowledge and skills could be learned from parents who could continue to contribute to a cumulative knowledge base on the 24-h management of children with behaviour problems and which might be useful to nurses and other professionals caring for these children.

- To identify the potential impact on the capacity of CAMH systems to respond to children with challenging behaviours if their parents become participants in creating and developing knowledge and skills, rather than just being recipients of professional knowledge and skills.

The parental study was undertaken as part of a series of parenting groups offered to parents as an additional service (Croom and Procter, 2005). Parents, therefore, contributed to the data collection whilst also receiving a service. At the outset of the study, a decision was taken to target parents of children most at risk of developing CAMH problems. Earlier literature had identified that these parents would have experience of the concept in their everyday parenting practice (Cunningham et al., 1995; Rae-Grant et al., 1989) but their attendance at parenting groups was sporadic with a high drop-out rate (Pugh and Smith, 1996).

The decision to focus on marginalized parents emphasized the importance of addressing the potential power differential between the group facilitators and the parents, identified in Box 1 as a key service delivery challenge. The issue of professional power was therefore central to the study, not as a known theoretical problem (Turner, 1995; Gabe et al., 1994; Johnson, 1995) but as a practice problem about which something had to be done within the methodological approach taken by the research.

This problem was addressed through the application of the principles of critical social theory. These principles were introduced as they explicitly incorporated the notion of practice change, in this case the parental practice change necessary to demonstrate the impact of the service on the users. This was achieved by getting both the researcher and the participants to focus on 'what could be rather than what is' (Thomas, 1993; Fontana, 2004) and through this process to identify the tacit assumptions and beliefs of the participants (both parents and facilitators), which may be experienced as oppressive. Critical social theory was thus used to develop emancipatory practice knowledge, ie, knowledge that is

Primary Health Care Research \& Development 2008; 9: 49-63 
emancipatory in the practice situation. Emancipatory knowledge can be described as 'that which attempts to reconcile and transcend the opposition between technical and practical knowledge. Emancipatory knowledge helps us to understand how social relationships are distorted and manipulated by relations of power and privilege. It also aims at creating the conditions under which irrationality, domination and oppression can be overcome and transformed through deliberative collective action' (McLaren, 1989) Thus, in this study, the parents were explicitly supported, as a group, to interrogate any potential tacit assumptions, at an individual, professional and societal level, which could possibly act to oppress them.

From a methodological perspective, the main challenge to the parental study was how to use the findings from the nursing study to inform the parenting study without distorting or silencing the parents' authentic experiences of childrearing. The findings from the nursing study were framed in terms associated with in-patient nursing practice. The parenting study required these findings to be transferred into a community context to provide a practice framework for the parenting groups. In order to achieve this, the findings from the nursing study were codified into four overarching propositions (Figure 1), which represented the concept analysis and key skill areas identified by the nurses. The propositions were used to frame the parenting groups. In order to test these propositions with parents, it was necessary to clearly explicate the nursing knowledge and skills underpinning each of them. This gave rise to sets of sub-propositions, which are given in Figure 2. The next section of the paper describes how the sub-propositions were derived and used to explore the reciprocal transfer of knowledge with parents.

\section{Attachment theory: its role and contribution to nursing care}

The nursing study illustrated that, provided the nurses could give the children alternative nurturing opportunities in which to develop a trusting attachment relationship, the children could use this relationship as a platform to help them develop control and strategies to cope with everyday limits and frustrations. This finding is supported by Clarke and Clarke (2000) and Rae-Grant et al. (1989) who identify the capacity for children to overcome their early adverse experiences, if they are provided with significantly better compensatory circumstances. These findings became a major motivating factor for the nurses in the first study as they indicated that their interventions could help these children progress towards health.

(1) That the nursing knowledge and skills derived from the nursing project (Croom 1996) will be useful to parents in their 24 hour context in the community, when caring for their child with behavioural problems.

(2) That the parents can refine and develop the nursing knowledge and skills (Croom 1996) and so add to a cumulative body of practice knowledge and skills related to the 24 -hour management of children with behavioural problems.

(3) That the parents can increase their capacity to respond effectively to their children with behaviour problems by gaining access to a diverse body of knowledge and by being participant researchers in the knowledge production process.

(4) That the service planners and providers can utilise parental knowledge, expertise and insight into caring for children with behavioural problems throughout their $\mathbf{2 4}$ hour life span in order to increase the systemic capacity to respond more appropriately and effectively to the needs of these children

Figure 1 Overarching propositions derived from nursing research (Croom et al., 2000) 
1.1. That developing a reciprocal attachment relationship, in which the child and their significant carer(s) become "in tune" with each other is essential to the management of children with emotional and behavioural problems

1.2. In order for carers to manage situations where their child is emotionally aroused/becoming out of control, the carers first need to manage the reciprocal arousal they feel themselves

1.3. There is a need to recognise that carers have feelings of ambivalence towards those they care for

1.4. Acknowledging and managing ambivalence is a healthy component of close relationships

1.5. Understanding how to help a child to "process information" in a way which enables him/her meet his/her social, developmental and emotional goals is essential. Articulating the knowledge and skills on the various micro stages in information processing are useful to carers in systematically supporting children with challenging behaviours. These micro processes include:

- Helping a child to "create a pause" in order to "stop and think" about the situation they were involved in

- Helping a child to selectively attend to social, emotional and situational cues in a range of situations

- Helping a child to consider a range of interpretations of these cues

- Helping a child to manage the emotional arousal which can arise from these interpretations

- Helping the child to be able to formulate the goal/ outcome, which they wish to achieve from a given situation, recall how they have previously coped in that kind of situation, think of alternative ways of coping and select a strategy which can help them achieve their chosen goal

- Helping a child to feel confident about being able to implement the chosen strategies to achieve their goal

- Helping a child to evaluate their performance and so learn from one situation to another.

1.6. That it is essential to understand and acknowledge that children who exhibit behavioural problems often have difficulties in expressing and also in appropriately seeking help when they are frustrated or distressed.

1.7. Knowledge and skills on peer relationships which nurses found useful in an inpatient setting such as high levels of supervision and teaching social skills will be useful for parents managing their children in their family setting within the community.

Figure 2 Sub-propositions tested in study with parents

Research, which highlighted that attachment relationships involve a reciprocal process (Schaffer, 1977; Stern, 1985; Sroufe, 1996), was important in enabling the nurses to understand the two-way nature of their relationships with the children in which they mutually influenced each others feelings and behaviours. The findings from the nursing research on attachment led to the formulation of two sub-propositions (Figure 2: 1.1 and 1.2).

\section{Ambivalence}

In their reflections on attachment, the nurses described how the children could engender powerful emotions in them through the process of reciprocal emotional arousal. Nurses indicated that this was because they had previously felt guilty as nurses/carers for 'not liking every child equally' and that they felt particularly guilty if they experienced negative feelings towards a child.

Primary Health Care Research \& Development 2008; 9: 49-63 
The literature was explored to check whether it could help nurses further negotiate a route through the moral complexity of this aspect of their practice. The work of Christine and Correia (1987) on maternal ambivalence helped the nurses to recognize how acknowledging any feelings of frustration or irritation about a child to another professional actually galvanized them into engaging in some positive interaction with the child. This finding highlighted the potential need to explore the literature on experiences of ambivalent feelings with parents. Sub-propositions 1.3 and 1.4 (Figure 2) were formulated from this finding.

\section{Information processing}

The information processing model of Crick and Dodge (1994), identified during the concept analysis, helped the nurses to articulate their tacit knowledge that children with challenging behaviours often had a sustained distorted view of reality in which they felt everybody was against them. This helped the nurses to explicate how they intuitively used the opportunities across $24-\mathrm{h}$ care to support the children to challenge their hostile attributions of social interactions and to explore alternative interpretations, which could stimulate them to formulate more prosocial goals in social interactions.

\section{The use of a pause to engage feedback}

Another perspective on control, identified through the concept analysis, was that of systems theory as developed in cybernetics. In systems theory control is modelled as a flow of information through systems with a feedback loop to detect error. Pauses and checks are included in the system to inform the feedback loop and to indicate whether adjustments are needed and, if so, in which direction (Dorf, 1967; George, 1967). Gaining a basic understanding of these models helped the nurses to appreciate the fact that children needed to be able to 'pause' or stop in order to gauge their level of emotional arousal and take preventative action before it overwhelms them. Nurses felt that they intuitively knew they had to support children to stop and think, but had not articulated this or integrated this tacit knowledge into systematic care plans,

Primary Health Care Research \& Development 2008; 9: 49-63 which could be shared with other professionals and carers. The findings from the research on information processing and systems theory led to the formulation of sub-proposition 1.5 (Figure 2).

\section{Help-seeking behaviour}

In addition to the literature identified in the concept analysis, nurses also identified skills and knowledge derived from their own practice experiences. Nurses possessed a tacit recognition of how difficult it can be for children with behaviour problems to proactively seek help. Through discussion and reflection on critical incidents, the nurses identified how a feature of the relationship they built with a child was the ability to intuitively tune into the child's non-verbal signals that they needed help, eg, a child may stand close to a nurse in order to indicate a need for help. On further reflection, the nurses recognized that as the child learned to trust that the nurse would be emotionally and physically there for them if they sought help, the child was more able to move on to verbal requests. The nurses found that systematically observing the child's progress from non-verbal to verbal signals for help represented significant therapeutic progress, which they had not previously recognized (Croom et al., 2000). They also found that describing this in multi-disciplinary groups enabled them to become better advocates for the child and to optimize the data arising from their 24-h observations. This formed the basis for the subproposition 1.6 (Figure 2).

\section{Peer relationships}

Reflection on and analysis of the nurses' practice experiences highlighted the importance of the child's peer relationships. Nurses identified that to promote peer relationship skills, they have to integrate a sophisticated understanding of how much the child was able to engage in a reciprocal trusting relationship, how much they were able to take on board information in order to negotiate or compromise, especially when emotionally aroused, and how competent they were in social interactions and with social skills. Nurses identified that this required high levels of supervision of the young people and their peer interactions in order to make judgements on when adult 
intervention was necessary and when the young people could be supported to use their own social skills with minimum promoting. A final subproposition 1.7 (Figure 2) was therefore developed.

\section{Parenting study}

In order to critically explore the reciprocal knowledge transfer process, the above propositions were tested out with parents in the parenting study using critical incidents and critical social theory embedded in a participatory action research cycle (see Figure 3). In addition, any other knowledge or literature (known to the facilitators or identified using electronic searches during the course of the study) that appeared to be relevant to solving the parents problems and making sense of their experiences was shared with parents. This represents the use of just-intime' knowledge transfer (Canadian Research Transfer Network, 2002). Here the facilitators/ researchers use techniques of knowledge brokerage to inform participants of key information, which is introduced to help them make sense of their current situation. This balanced the use of knowledge valued by professionals and codified in the nursing framework by identifying, using and therefore increasing the value of different evidence which the parents identified as useful. Parents were therefore able to increase the range of formal knowledge used in the local system of health care delivery, increasing the value of knowledge that had previously been neglected by professionals.

A total of eight cohorts of parents were engaged over a series of eight consecutive groups. Each group had 12-14 sessions. The minimum number attending a group session was one and the maximum was five. Twenty-five parents (all female) out of an initial 75 invited to attend, attended at least $75 \%$ of the sessions, including the first and last session. Data were collected from the 25 parents who attended at least $75 \%$ of the sessions.

Inclusion criteria were derived using the Pearce (1993) criteria for identifying CAMH problems. These include:

- behaviour problems which result in the child being able to cope with everyday frustrations and stresses in a way which inhibits their social and emotional development to a level that required referral to a CAMH service;

- that these problems had lasted for at least a month and caused significant distress to the family on a daily basis.

In addition, purposeful sampling was used to identify parents in socio-economically deprived areas of the city as these parents are most likely to drop out of parenting groups and therefore provide a way of discovering how transferable the knowledge is to the most vulnerable clients. Table 1 illustrates the socio-economic and educational vulnerability of these parents; it indicates that the parents who participated match the characteristics of those identified in research (Cunningham et al., 1995) to be the least likely to access services.

\section{Findings}

In the course of the research, the parents brought along a range of issues and critical incidents related to the challenging behaviours of their child. The group then explored how they could be understood, eg, one parent described an incident in which a child kicked his sister when he was asked to come for his meal. The parent's initial interpretation of the situation was that the child was deliberately winding her and his sister up. The introduction of the action component of the research, ie, the nursing practice framework and additional literature on temperament (Turecki and Tonner, 2000), helped the parents in the group to consider alternative interpretations/ understandings of the child's behaviour. This enabled them to consider that the child may have genuine difficulties with changing activities because of his innate temperament. Strategies to cope with this, identified in the nursing practice framework, were shared with the parents, for example that he be given a transitional warning prior to changing any activity (Turecki and Tonner, 2000). The parents unanimously found that access to knowledge on temperament was useful. Combining this with the knowledge from the nursing study on attachment helped them to 'tune into' their children's individual temperamental profile and to recognize that their children were often being judged according to a narrow set

Primary Health Care Research \& Development 2008; 9: 49-63 


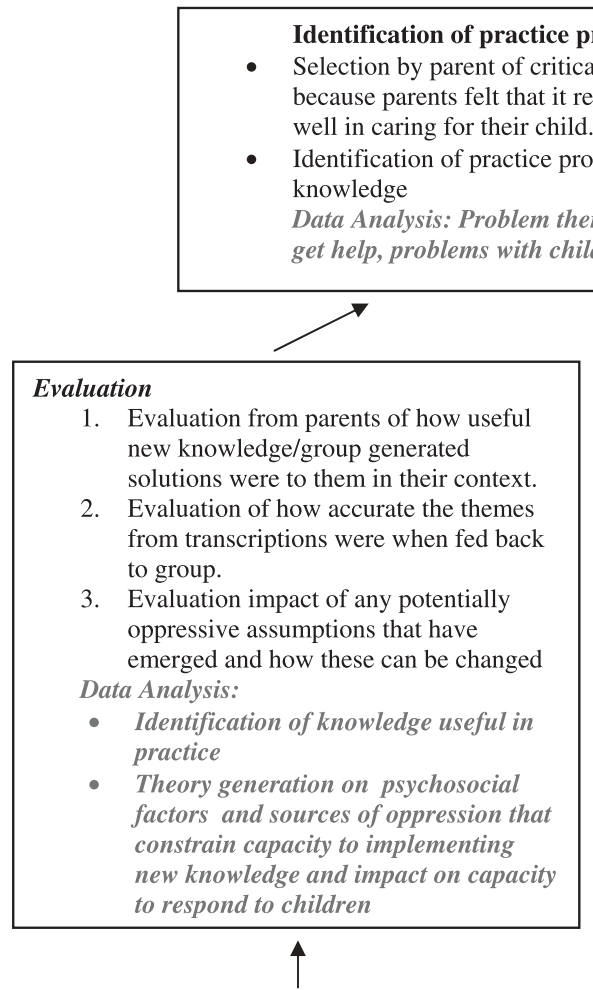

Refinement of knowledge and skills: 1. Parameters of relevance of nursing knowledge and skills in community context 2. Knowledge on how to cope with potential oppression

Iterative evolution of practice framework incorporating:

i) Refinement of propositions

ii) New themes emerging from experiential experiences of parents

iii) Additional literature which is found to be useful (e.g. temperament)

iv) What parents can teach professionals v) Capacity for increasing potential of parents and professionals and services to respond to children with disruptive behaviour problems

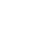

\section{Action}

1. Discussion by group on how the solutions can be applied to their community context

2. Testing out this solution in their actual community context. (reflection in action)

3. Transcription of group discussion:

Identification of themes and analysis of emerging themes by researcher.

Data Analysis: Identification of solutions arising from increased understanding and their exploration of what they would fid useful with their child e.g. how to apply this in parents' context e.g. do a study of their child, give transitional warning, acknowledge awareness of their ambivalence, challenge oppressive assumptions by changing their own beliefs, going into school and challenging ideas that all children should be treated the same or challenging sense of blame from neighbours

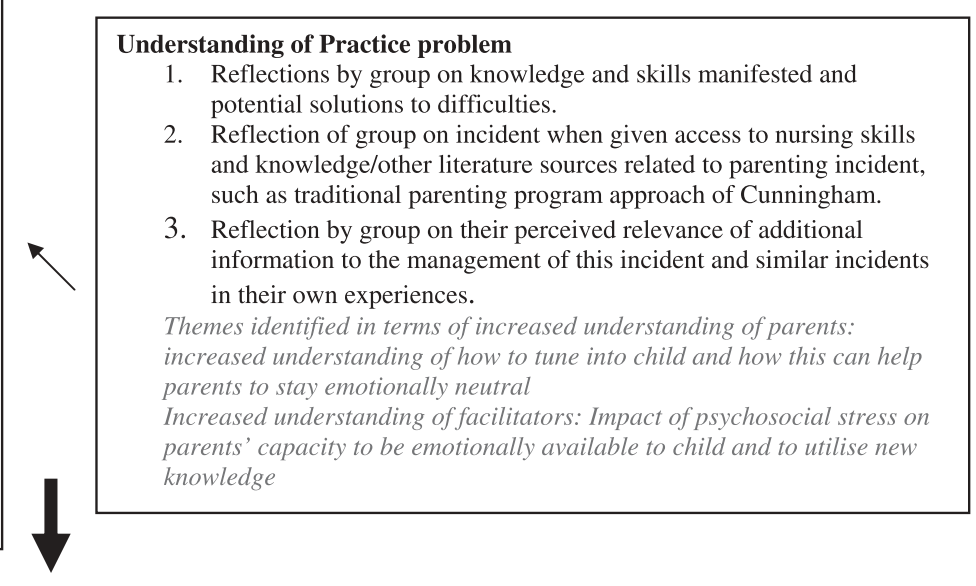

Iteratively evolving Practice framework

1. Synthesises themes emerging from data analysis.

2. Provides tentative framework of knowledge and skills, which are can be generatively explored and iteratively revised

3. Provides action plan, which is grounded in participant action research with parents

Figure 3 Diagram to illustrate how data was analysed through reflective action cycles 
Table 1 Social characteristics of parents invited to participate in the research and those who participated

\begin{tabular}{|c|c|c|c|c|}
\hline $\begin{array}{l}\text { Social Characteristics of } \\
\text { Parents invited and those } \\
\text { who became active research } \\
\text { participants }\end{array}$ & $\begin{array}{l}\text { Parents } \\
\text { invited to } \\
\text { participate }\end{array}$ & $\begin{array}{l}\text { Parents, from } \\
75 \text { invited who } \\
\text { agreed to } \\
\text { attend }\end{array}$ & $\begin{array}{l}\text { Parents, from } 50, \text { who } \\
\text { agreed to attend, who } \\
\text { only attended first } \\
\text { session of group, but did } \\
\text { not attend subsequent } \\
\text { sessions }\end{array}$ & $\begin{array}{l}\text { Parents who became } \\
\text { active research } \\
\text { participants and } \\
\text { attended } 75 \% \text { of } \\
\text { sessions }(n=25)\end{array}$ \\
\hline Gender & 75 female & 50 all female & 20 female & 25 female \\
\hline Owner occupied house & 1 & 1 & 0 & 1 \\
\hline $\begin{array}{l}\text { Council/rented } \\
\text { accommodation }\end{array}$ & 74 & 49 & 20 & 24 \\
\hline $\begin{array}{l}\text { Educational qualifications } \\
\text { beyond } 16\end{array}$ & 1 & 1 & 0 & 1 \\
\hline $\begin{array}{l}\text { National Vocational } \\
\text { Qualification }\end{array}$ & 1 & 1 & 0 & 1 \\
\hline Single parents & 74 & 44 & 20 & 24 \\
\hline Married & 1 & 1 & 0 & 1 \\
\hline Living on social assistance & 74 & 49 & 20 & 24 \\
\hline Employed & 1 & 1 & 0 & 1 \\
\hline
\end{tabular}

of constructed behavioural norms. This knowledge enabled some of the parents to challenge their previously tacit assumption that children who did not conform to society's norms were deliberately naughty.

However, despite all of the parents having had significant multi-agency service contact prior to the referral to $\mathrm{CAMH}$ services, none of the parents had previously been introduced to knowledge on temperament. Using critical theory, the parents were supported to reflect on what 'could be' rather than 'what is'. This helped parents to identify some tacitly oppressive assumptions in the local systems of care, for example that parents of children who had difficulties conforming to constructed norms at school (such as all children should be able to sit quietly for 35-min periods) were failing in being able to socialize their child to appropriate behaviours. This sense of failure was universal across the cohorts and led to increasing social isolation and guilt. Using knowledge on temperament helped parents to interrogate these assumptions. However, some of the parents found that this knowledge transfer was useful but not sufficient to change their parenting practice. A number of reasons for this were identified.

At an individual level, parents found that they could only apply the knowledge about effectively tuning into their children when they themselves were feeling calm and supported. They identified a number of stressors such as neighbourhood harassment, socio-economic factors, social isolation and depression that inhibited this process. At a systemic level, the parents identified that although the literature on temperament was available in academic and professional journals it did not form part of the local knowledge system informing schools or GP practices. Some of the parents were able to successfully share knowledge about temperament with their child's schoolteacher and use this understanding to transform a previously hostile relationship with the teacher into a shared partnership to support the child. Other parents, however, found profound professional resistance from schools to knowledge transfer from parents about temperament. At a service delivery level, there did not seem to be sufficient resources to sustain taking the individual approach to children designed to promote a fit between the child's temperamental needs and his/her environment as recommended in the NSF. Evidence suggests that lack of fit creates insensitive responses to a child with a challenging temperament and increases their risk of school and social exclusion (Churchill, 2003; Chess and Thomas, 1999).

Overall the findings from the analysis indicated that the knowledge transferred from the published literature and the nursing practice framework was useful but not sufficient in developing parental practice solutions and developing Primary Health Care Research \& Development 2008; 9: 49-63 
parental capacity to respond to their child's needs. The following factors were identified as limiting parental responses:

- Lack of material resources.

- Tacit oppression in system.

- Failure to disseminate the findings of research, which the parents found relevant to their situation, across the system to include schools, leisure facilities and social services.

- Lack of group consciousness among parents of these children and lack of awareness of inappropriate attribution of behaviours as naughty rather than arising from temperament, the awareness of which enabled some of the parents to address these problems with significant carers such as teachers and grandparents.

However, although some parents did learn to challenge systems, they identified that changes needed to take place at a service delivery (doing) level if their capacity as parents to meet the needs of these children is to be developed.

\section{Development of a methodology for reciprocal knowledge transfer between carers and professionals}

This section will identify the practice and methodological tensions to engaging in reciprocal knowledge transfer not only with fellow professionals but also with parents who were simultaneously clients of a CAMH system, and the solutions to these tensions adopted in this research.

The first challenge was how to access experiential knowledge of professionals who have developed expertise, which was taken for granted and intuitive. The solution developed in the nursing study was to use published knowledge, structured using a concept analysis, as a tool to interrogate practice experiences and facilitate the articulation of tacit taken-for-granted experiential knowledge (Croom et al., 2000). In extending this method to parents, the emerging nursing knowledge and skills were converted into propositions (described above) that were then used with parents to critically interrogate their parenting experiences and to identify the parameters of the

Primary Health Care Research \& Development 2008; 9: 49-63 transfer of nursing knowledge useful in their parenting context.

A second challenge was how to access authentic experiential data which are grounded in real-life experiences and therefore provide the medium for testing out the relevance of codified formal knowledge to practice/real-life situations. Critical incident technique allows participants to focus in on their own experiences and use narratives of their everyday practice and experience. Themes emerging from the analysis of these data can help to identify critical skills (Flanagan, 1954; Norman et al., 1992). This method used with nurses was found to be transferable to parents.

A third challenge was how to engage vulnerable hard-to-reach parents in research. The solution adopted here was to deliver services simultaneously with research and so attempt to engage in reciprocal knowledge transfer in situ by offering a service that could meet clients' needs whilst simultaneously giving them a research voice that could support them to be creators and not just users of services.

A fourth challenge was the acknowledged tendency of vulnerable groups to echo the voice of the most powerful (Gaventa and Cornwall, 2001). The parents, who were also clients of a CAMH service, could feel vulnerable/oppressed by professional researchers and hence say what they felt the researchers wanted to hear. The solution used in this study was to develop parenting research groups that lasted 12 weeks in order to allow the development of group cohesiveness and consciousness. In addition, the application of a critical theory (Fontana, 2004) perspective facilitated an exploration of any tacit or overt oppression within the current evidence base and/ or the interactions with the researchers. Converting the professional practice knowledge base to a series of propositions meant that each proposition could be inductively analysed with the parents according to whether the knowledge underpinning the proposition was valuable when applied to the parents' actual parenting experiences. The length of the groups enabled completion of a series of action cycles in which parents could test out and reinforce their experiences with each other and not just with researcher/ practitioners.

A fifth methodological challenge was how to delineate research data from the plethora of 


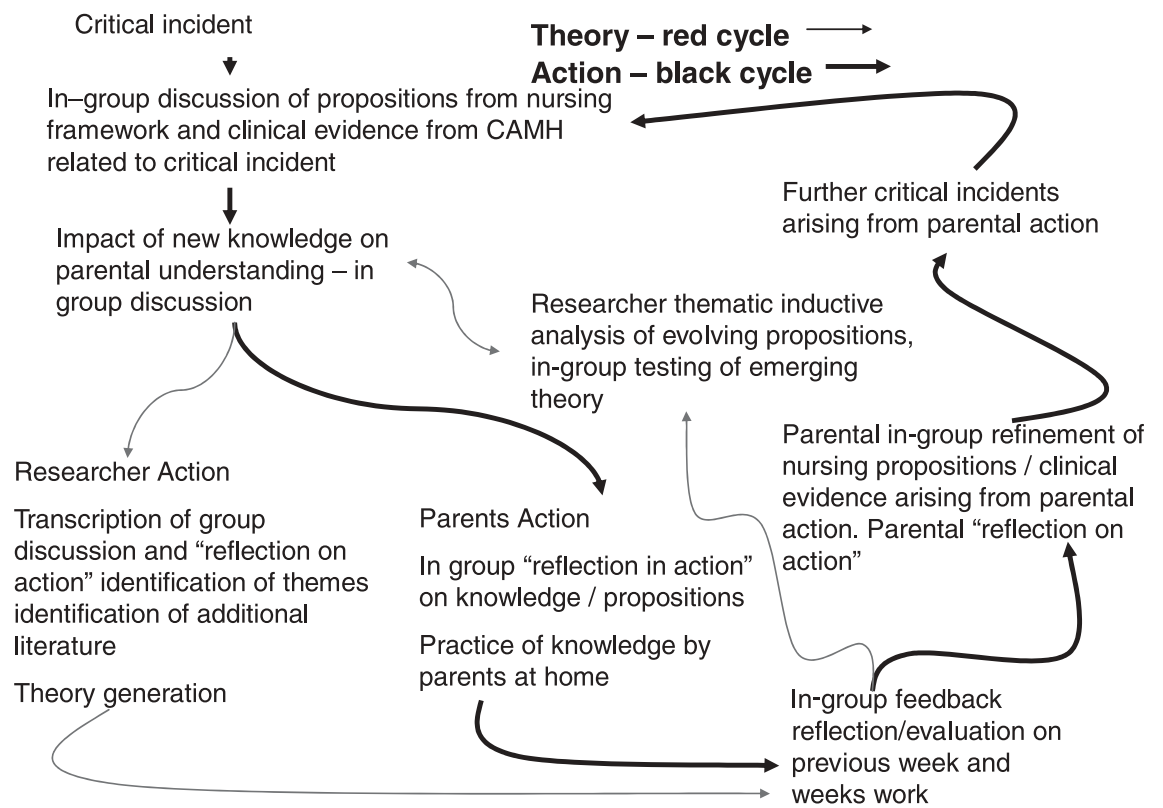

Figure 4 Action research cycle

practice data that emerges in a group over 12 weeks. The solution adopted was to use purposeful sampling of data using completed action research cycles (see Figure 4). Therefore only data appertaining to completed cycles of action were included in the analysis of the parenting study.

A sixth methodological and ethical challenge was how to ensure parents received a quality service as well as participating in research. The solution adopted was to provide access to a wide range of knowledge in addition to the nursing knowledge according to issues which parents raised through their ongoing experiences.

\section{Conclusion}

This paper has described how a body of practice knowledge can be built and how established scientific and academic knowledge can be used and modified in particular contexts to meet particular needs. It demonstrates how 'just-in-time' knowledge-transfer techniques (Canadian Research Transfer Network, 2002) can be embedded within more systematic and evidence-based approaches to action research. This enables knowledge valued by service users to be incorporated into the knowledge systems informing professional practice.

From both a practice and research perspective, the issue of sustaining support for parents was important and represents a further system challenge. Despite the approach taken, only 25 of the 75 parents referred to the service were able to sustain the programme, reflecting similar problems of accessing hard-to-reach groups identified in previous CAMH studies (Pugh and Smith, 1996).

Current health contexts are characterized by high needs and finite resources and policy requirements to incorporate user views and participation. However, the service delivery challenges given in Box 1, and inherent oppression identified by service users in this study are rarely acknowledged. This paper demonstrates that elements of the social constructionist perspective on knowledge transfer advocated by Bate and Robert (2002) and McAdam and Reid (2001) can be used to facilitate knowledge transfer between service organizations and users. Of particular value were the codification of tacit user knowledge and the transfer of knowledge valued by service users into the practice system.

Primary Health Care Research \& Development 2008; 9: 49-63 
However, if the social constructionist approach is to address the challenges of optimizing service delivery identified in Box 1 it must move beyond discussions of organizational knowledge management and recognize the crucial importance of including service users in the creation and construction of knowledge for practice. The reciprocal transfer of knowledge described in this paper describes one example of how this can be achieved and may go some way to addressing the 'know-do' gap (WHO, 2006).

\section{References}

Agyris, C. 1993: Knowledge for action: a guide to overcoming barriers to organisational change. San Francisco, CA: Josey Bass.

Audit Commission. 1999: Children in mind. London: HMSO.

Bate, S.P. and Robert, G. 2002: Knowledge management and communities of practice in the private sector: lessons for modernizing the National Health Service in England and Wales. Public Administration 80, 643-63.

Baumard, P. 1999: Tacit knowledge in organisations. London: Sage.

Canadian Research Transfer Network. 2002. Knowledge transfer in health. Report of a two day conference. Retrieved 30 October 2006 from www.chsrf.ca/ knowledge_transfer/pdf/ktransfer2002_e.pdf

Caspi, A., Henry, B., McGee, R.O., Moffitt, T.E. and Silva, P.A. 1995: Temperamental origins of child and adolescent behaviour problems: from age three to age fifteen. Child Development 66, 55-68.

Centre for Reviews and Dissemination. 2001: Understanding Systematic Reviews of Research Effectiveness Centre for Reviews and Dissemination guidance for those carrying out or commissioning reviews. CRD Report No. 4, second edition, March 2001, University of York.

Chess, A. and Thomas, A. 1999: Goodness of fit: clinical applications from infancy through adult life. Philadelphia: Brunner Mazel.

Christine, G. and Correia, A. 1987: Maternal ambivalence in a group psychoanalytical setting. British Journal of Psychotherapy 3, 205-15.

Churchill, S.L. 2003: Goodness of fit in early childhood settings. Early Childhood Education Journal 31, 113-18.

Clarke, A. and Clarke, C. 2000: Early experiences and the life path. London: Jessica Kingsley.

Cochrane, A.L. 1972: Effectiveness and efficiency: random reflections on health services. Nuffield Provincial Hospitals Trust.

Crick, N. and Dodge, K. 1994: A review and reformulation of social information processing. Psychological Bulletin, pp. 74-101.

Primary Health Care Research \& Development 2008; 9: 49-63
Croom, S. and Procter, S. 2005: The NewCan Practice Framework: using risk and resilience to work at the interface between professional expertise and parental knowledge and experience in child and adolescent mental health. Practice 17, 113-26.

Croom, S., Procter, S. and Le Couteur, A. 2000: Developing a concept analysis of control for use in child and adolescent mental health nursing practice. Journal of Advanced Nursing 31, 1324-332.

Cunningham, C., Bremner, R. and Boyle, M. 1995: Large group community based parenting program for families of pre-schoolers at risk of disruptive behaviour disorders: utilisation of cost effectiveness and outcome. Journal of Child Psychology and Psychiatry 36, 1141-159.

Cunningham, C., Bremner, R. and Secord, M. 1996: The Community Parent Education Program. Canada: Leaders Manual COPE Works Press, McMaster University.

Cutcliffe, J.R. and McKenna, H.P. 2005: The evolution of concept analysis - where do we go from here? In Cutcliffe, J.R. and McKenna, H.P., editors, The essential concepts of nursing. Edinburgh: Elsevier Churchill Livingstone, 349-61.

Davenport, T.H. and Prusak, L. 1998: Working knowledge: how organisations manage what they know. Boston: Harvard Business School Press.

Department of Health and Department for Education and Skills. 2004: National Service Framework for Children, Young People and Maternity Services. Standard 9: The mental health and psychological well being of children and young people. London: Department of Health.

Dorf, R. 1967: Control Systems Theory. London: Heineman.

Flanagan, J. 1954: The Critical Incident technique. Psychological Bulletin 51, 327-58.

Fontana, J.S. 2004: A methodology for Critical Science in Nursing. Advances in Nursing Science 27, 93-101.

Gabe, J., Kelleher, D. and Williams, G. 1994: Challenging Medicine. London: Routledge.

Gaventa, G. and Cornwall, A. 2001: Power and Knowledge. In Reason, P. and Bradbury, H., editors, Handbook of action research. London: Sage, 70-80

George, F.H. 1967: The foundation of cybernetics. London: Heineman.

Health Advisory Service. 1995: Child and Adolescent Mental Health Services Together we stand: An NHS Advisory Service Thematic Review. London: HMSO.

Henggeler, SW., Schoenwald, S.K. and Pickrel, S.G. 1995: Multi-systemic therapy: bridging the gap between university and community based treatment. Journal of Consulting and Clinical Psychology 63, 709-5717.

INVOLVE. Retrieved 5 September 2007 from http:// www.invo.org.uk/Database.asp

Johnson, T. 1995: Governmentality and the institutionalization of expertise. In Johnson, T., Larking, G. and Saks, M., editors, Health professionals and the state in Europe. London: Routledge, 7-24. 
Kemmis, S. and McTaggart, R. 2000: Participatory action research. In Denzin, N.K. and Lincoln, Y.S., editors, Handbook of qualitative research. Thousand Oaks: Sage Publications, 567-605.

Khanlou, N. and Peter, E. 2005: Participatory action research: considerations for ethical review. Social Science and Medicine 60, 2333-340.

Knapp, M., Scott, S. and Davies, J.J. 1999: The Cost of antisocial behaviour on younger children: a pilot study of economic and family impact. Clinical Child Psychology and Psychiatry 4, 457-83.

Maturana, H.R. 1991: Science and daily life: the ontology of scientific explanations. In Steier, F., editor, Research and reflexivity. London: Sage, 30-52.

McAdam, R. and Reid, R. 2001: SME and large organisation perceptions of knowledge management: comparisons and contrasts. Journal of Knowledge Management 5, 231-41.

McLaren, P. 1989: Life in schools: introduction to critical pedagogy. New York: Irwin.

Mental Health Foundation. 1999: Bright Futures: Promoting Children and Young People's Mental Health. London: Mental Health Foundation.

Miller, W.L. and Crabtree, B.F. 2000: Clinical Research. In Denzin, N.K. and Lincoln, Y.S., editors, Handbook of qualitative research, second edition, London: Sage, 607-31.

Muir Gray, J.A. 1997: Evidence-based healthcare: how to make health policy and management decisions. Edinburgh: Churchill Livingstone.

Norman, I.J., Redfern, S.J., Tomalin, D.A. and Oliver, S. 1992: Developing Flanagan's critical Incident technique to elicit indicators of high and low quality nursing care from patients and their nurses. Journal of Advanced Nursing 17, 590-600.

Office of National Statistics, Green, H., McGinnity, A., Meltzer, H. and Ford, T. 2005: Mental health of children and young people in Great Britain 2004. London: Palgrave Macmillan.

Pawson, R., Greenhalgh, T. and Harvey, H. 2004: Realist synthesis: an introduction. ESRC Working Papers. Manchester: Manchester University.

Pearce, J. 1993: Child health surveillance for psychiatric disorder: practical guidelines. Archives of Diseases in childhood 69, 394-98.

Prillitinsky, I. 2001: Value based praxis in community psychology: moving towards social justice and social action. American Journal of Community Psychology 29, 747-78.

Probst, G., Doughty, H.A. and Raub, S. 2000: Managing knowledge: building blocks for success. Chichester: J. Wiley.
Pugh, G. and Smith, C. 1996: Learning to be a parent: a survey of group based parenting programmes. London: Family Policies Studies Centre.

Rae-Grant, N., Thomas, B.H., Offord, D.R. and Boyle, M.H. 1989: Risk, protective factors, and the prevalence of behavioural and emotional disorders in children and adolescents. American Academy of Child and Adolescent Psychiatry 262-268.

Reed, J. and Biott, C. 1995: Evaluating and developing practitioner research. In Reed, J. and Procter, S., editors, Practitioner research in health care. London: Chapman and Hall, 189-208.

Rolfe, G. 2000: Research, truth, authority: postmodern perspectives on nursing. London: Macmillan Press Ltd.

Ryecroft-Malone, J., Seers, K., Titchen, A., Harvey, G., Kitson, A. and McCormack, B. 2004: What counts as evidence in evidence-based practice. Journal of advanced Nursing 47, 81-90.

Sackett, D.L. and Rosenberg, W.M.C. 1995: The need for evidence-based medicine. Journal of the Royal Society of Medicine 88, 620-24.

Schaffer, R. 1977: Mothering. Cambridge, MA: Harvard University Press.

Schon, D. 1983: The reflective practitioner. London: Temple Smith.

Schon, D. 1987: Educating the reflective practitioner. San Francisco: Jossey Bass.

Stern, D. 1985: The interpersonal world of the infant. New York: Basic Books.

Stewart, T.A. 2002: The wealth of knowledge: intellectual capital and the twenty first century organisation. London: Currency Doubleday.

Sroufe, L.A. 1996: Emotional development: the organisation of emotional life in the early years. Cambridge: Cambridge University Press.

Thomas, H. 1993: Critical ethnography. London: Sage Publications.

Turecki, S. and Tonner, L. 2000: The difficult child, second edition. New York: Bantum Books.

Turner, B.S. 1995: Medical power and social knowledge, second edition. London: Sage.

Webster-Stratton, C. 1998: Preventing conduct problems in Head Start children: strengthening parenting competencies. Journal of Consulting and Clinical Psychology 56, 558-66.

Wenar, C. 1982: Psychopathology from infancy to adolescence. Rand House Inc.

World Health Organization 2006: Bridging the 'Know-Do Gap' meeting on knowledge translation in global health. Geneva: WHP. 